\title{
3D Vector Reconstruction of the Neck Skeleton from the Anatomical Sections of Korean Visible Human at the Anatomical Laboratory of Paris Descartes
}

\author{
Abdoulaye Kanté1,2*, Mariam Daou ${ }^{2,3}$, Jean François Uhl' ${ }^{1}$, Vincent Delmas ${ }^{1}$, Babou Ba ${ }^{2}$, \\ Tata Touré2, Ousmane Touré ${ }^{2}$, Moumouna Koné2, Demba Yatera ${ }^{2}$, Youssouf Sidibé4, \\ Drissa Traoré2, Bréhima Coulibaly², Nouhoum Ongoïba² \\ ${ }^{1}$ Anatomy Laboratory, University of Paris 5, Paris, France \\ ${ }^{2}$ Anatomy Laboratory, University of Sciences, Techniques and Technologies of Bamako, Bamako, Mali \\ ${ }^{3}$ Department of Neurology, Gabriel Touré University Hospital in Bamako, Bamako, Mali \\ ${ }^{4}$ Faculty of Medicine and Odontostomatology, Bamako, Mali \\ Email: *kanteim@yahoo.fr
}

How to cite this paper: Kanté, A., Daou, M., Uhl, J.F., Delmas, V., Ba, B., Touré, T., Touré, O., Koné, M., Yatera, D., Sidibé, Y., Traoré, D., Coulibaly, B. and Ongoïba, N. (2021) 3D Vector Reconstruction of the Neck Skeleton from the Anatomical Sections of Korean Visible Human at the Anatomical Laboratory of Paris Descartes. Forensic Medicine and Anatomy Research, 9, 41-53.

https://doi.org/10.4236/fmar.2021.94005

Received: June 14, 2021

Accepted: August 28, 2021

Published: September 1, 2021

Copyright $\odot 2021$ by author(s) and Scientific Research Publishing Inc. This work is licensed under the Creative Commons Attribution International License (CC BY 4.0).

http://creativecommons.org/licenses/by/4.0/ (c) (i) Open Access

\begin{abstract}
Aim: To perform a vector 3D reconstruction of the neck skeleton from the anatomical sections of the "Korean Visible Human" for educational purposes. Material and Methods: The anatomical subject was a 33-year-old Korean male who died of leukemia. It measured $164 \mathrm{~cm}$ and weighed $55 \mathrm{kgs}$. The anatomical cuts were made in 2010 after an MRI and a CT scan. A special saw (cryomacrotome) made it possible to make cuts on the frozen body of $0.2 \mathrm{~mm}$ thick or 5960 slices. Sections numbered 1500 to 2000 (500 neck sections) were used for this study. Manual contouring segmentation of each anatomical element of the anterior neck area was done using Winsurf software version 3.5 on a PC. Results: Our vector 3D neck model includes the following: cervical vertebrae, hyoid bone, sternum manubrium and clavicles. This vector model has been integrated into the virtual dissection table Diva3d, a new educational tool used by universities and medical schools to learn anatomy. This model was also put online on the Sketchfab website and printed in 3D using an ENDER 3 printer. Conclusion: This original work is a remarkable educational tool for the study of the skeleton of the neck and can also serve as a $3 \mathrm{D}$ atlas for simulation purposes for training therapeutic gestures.
\end{abstract}

\section{Keywords}

Neck Skeleton, Korean Visible Human, 3D Vector Modeling, Virtual Dissection 
Table Diva3d, Teaching

\section{Introduction}

The neck is the area of the body between the head and chest [1]. It supports and gives the head its mobility, allows passage to several visceral elements of the nervous system, digestive, ventilatory and phonatory, allows vascularization of the head and plays a role in the general and phosphocalcic metabolism [1].

The skeleton of the neck includes the cervical vertebrae, hyoid bone, the manubrium of the sternum and the clavicles. The clavicles belong to the upper appendicular skeleton; the cervical vertebrae, the sternal manubrium and the hyoid bone are part of the axial skeleton [2].

Neck pathologies are many and varied. Their understanding and therapeutic management require a good command of the cervical anatomy in general and in particular the osteology of the neck. We conducted this study with the objective of achieving a 3D vector reconstruction of the neck skeleton from anatomical sections of the "Korean Visible Human" in order to design a 3D tool for teaching neck osteology.

\section{Methodology}

The material used for vector D3 reconstruction is the anatomical slices of the "Korean Visible Human".

The Korean Visible Human is a man of Korean nationality, who died of leukemia at the age of 33 who gave his body to science. It measured $164 \mathrm{~cm}$ and weighed $55 \mathrm{kgs}$ (Figure 1) [3] [4] [5] [6].

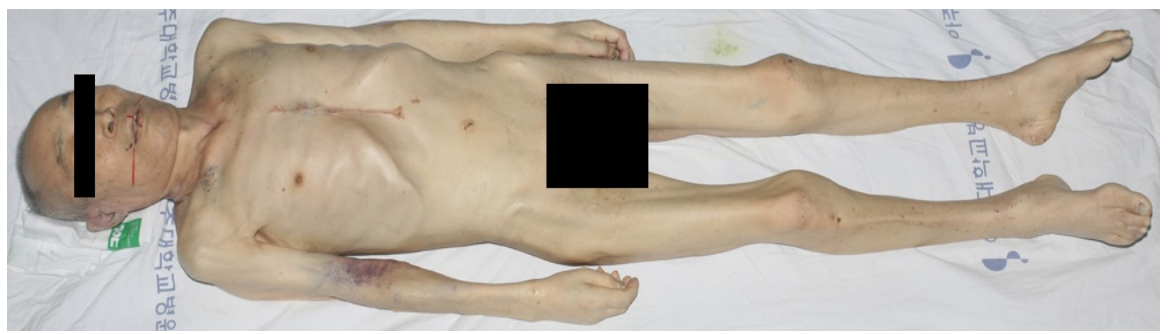

Figure 1. Anatomical subject that obtained anatomical slices.

The anatomical slices were made in 2010 after an MRI and a CT scan. A special saw (cryomacrotome) made it possible to make cuts on the frozen body of $0.2 \mathrm{~mm}$ thick or 5960 slices. Sections numbered 1500 to 2000 (500 neck sections) were used for this study (Figures 2-4).

A manual contouring segmentation of each neck bone structure was performed using Winsurf software version 3.5 on a Windows 7 laptop with 8 gigas Ram (Figure 5 \& Figure 6). After the manual segmentation, we used Photoshop to insert the caption on the $3 \mathrm{D}$ objects. 


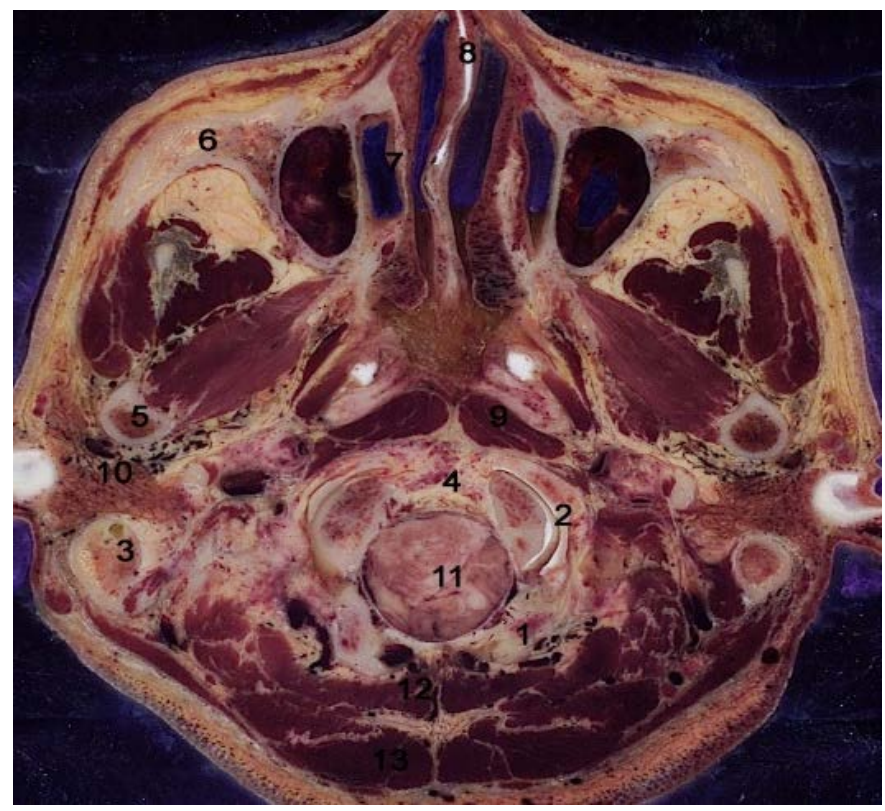

Figure 2. Horizontal anatomical section of KVH through the atlas. (1. Occipital; 2. Occipito-Atloid joint; 3. Mastoid process; 4. Upper extremity of the odontoid process; 5. Mandible; 6. Zygomatic process; 7. Nasal pits; 8. Septum of the nasal pits; 9. Great anterior right muscle; 10. Parotid gland; 11. Elongated marrow; 12. Semi-spiny head muscle; 13. Trapezium muscle).

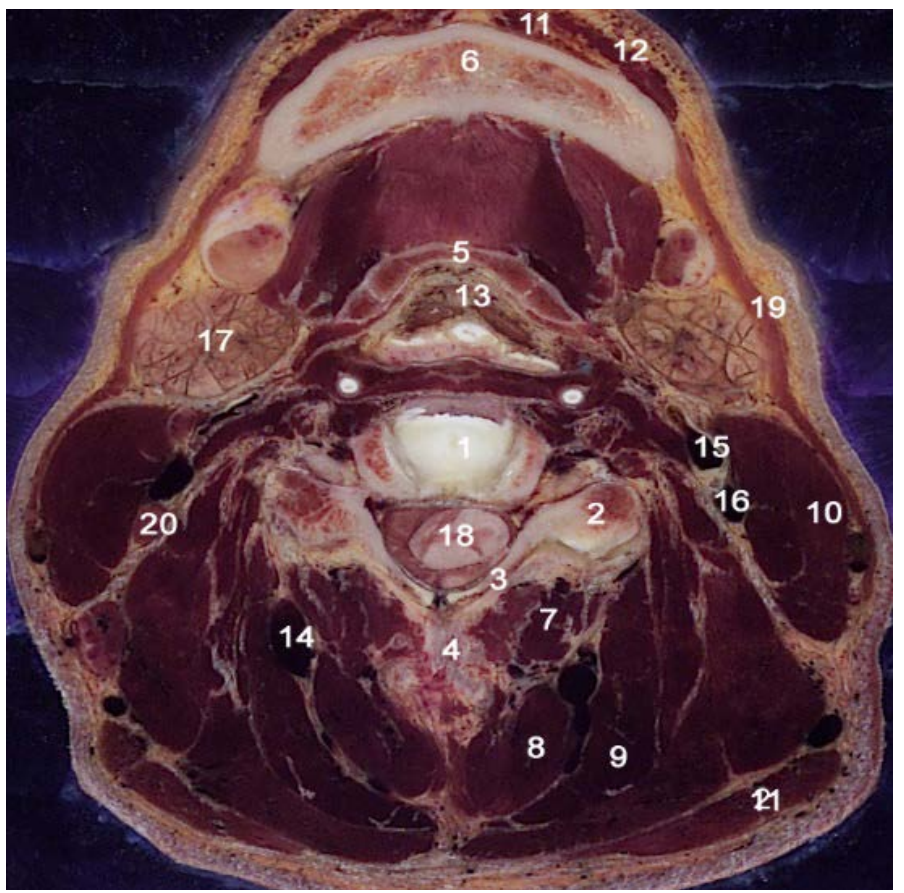

Figure 3. Horizontal anatomical slice of KVH through C4. (1. Vertebral body; 2. Transverse process; 3. Lama; 4 . Spiny process; 5 . Hyoid bone body; 6 . Mandible; 7. Spiny transverse neck muscle; 8. Semi-spiny head muscle; 9. Splenic head muscle; 10. Sterno-cleido-mastoid muscle; 11. Genio-hyoid muscle; 12. Mylo-hyoid muscle; 13. Vocal cord; 14. Deep cervical artery; 15. External carotid artery; 16. Internal carotid artery; 17. Mandibular gland; 18. Cervical marrow; 19. Peaucier muscle; 20. Jugular lymph node; 21. Trapezium muscle). 


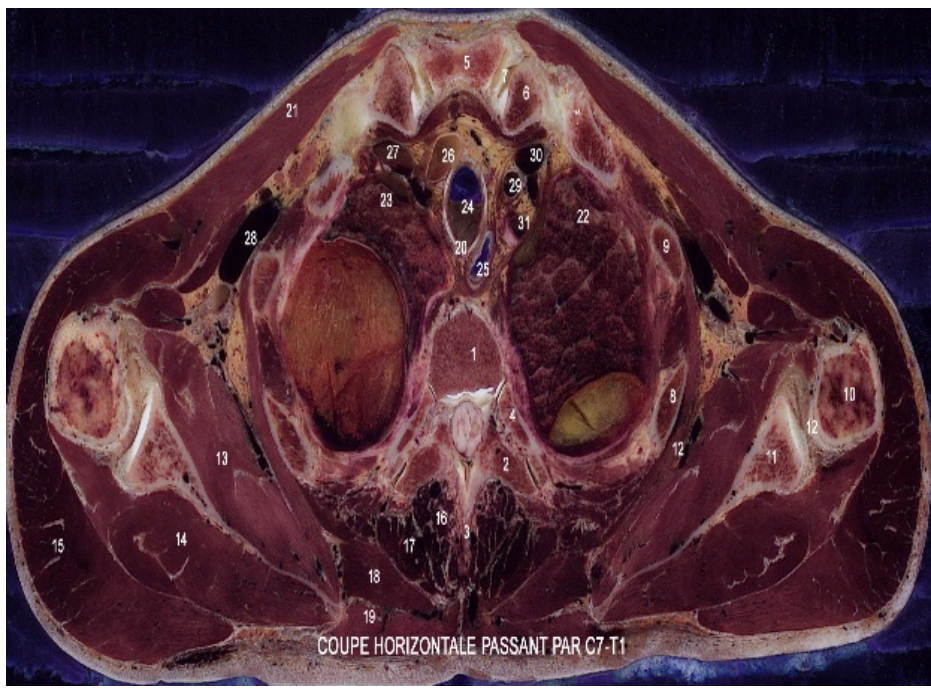

Figure 4. Horizontal anatomical slice of KVH through C7-T1. (1. Vertebral body; 2. Transverse process of the first thoracic vertebra; 3 . Spiny process; 4 . First rib; 5 . Sternal manubrium; 6. Clavicle; 7. Sternoclavicular joint; 8. Rib; 9. Rib; 10. Humeral head; 11. Scapula; 12. Anterior serrated muscle; 13. Subscapular muscle; 14. Supra-spine muscle; 15. Deltoid muscle; 16. Transverse spiny muscle; 17. Longissimus head muscle; 18. Trapezium muscle; 19. Trapezium muscle; 20. Vagus nerve; 21. Pectoral muscle; 22. Left upper pulmonary lobe; 23. Right upper pulmonary lobe; 24 . Thoracic trachea; 26 . Thoracic esophagus; 27. Right brachio-cephalic venous trunk; 28. Subclavian vein; 28. Subclavian vein; 29. Left common carotid artery; 30. Left brachiocephalic vein trunk; 31. Left subclavian artery).

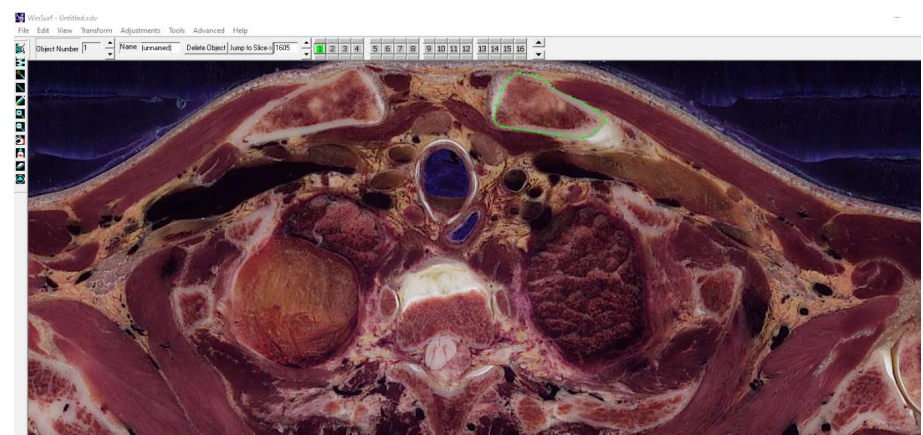

Figure 5. Contouring of the left clavicle on anatomical slice no. 1605 (2D) from Winsurf using the "pencil".

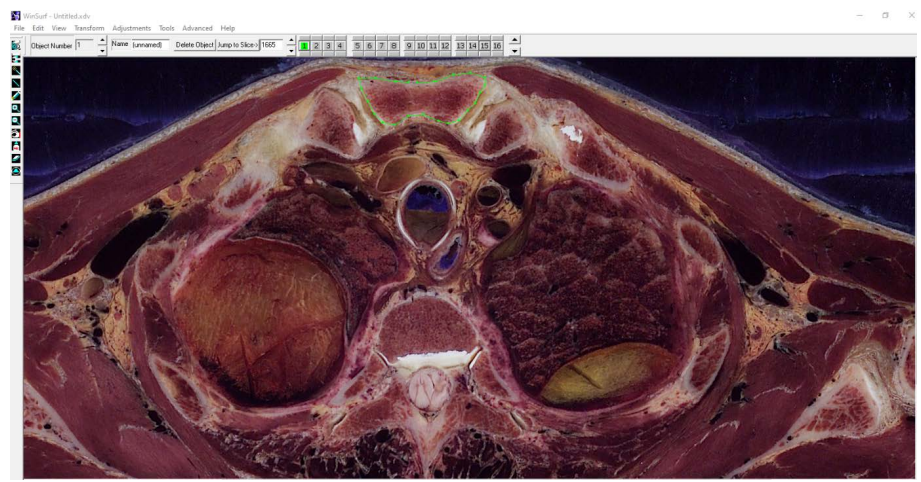

Figure 6. Contour of the sternum on the anatomical section no. 1665 (2D) from Winsurf using the "pencil". 


\section{Results}

The methodology used allowed us to reconstruct the cervical vertebrae, hyoid bone, sternal manubrium and clavicles. We will first introduce the $3 \mathrm{D}$ vector reconstruction of the cervical vertebrae. Then, we will present the $3 \mathrm{D}$ vector reconstruction of the hyoid bone, the sternal manubrium and eventually present the $3 \mathrm{D}$ reconstruction of the clavicles.

\subsection{D Vector Reconstruction of Cervical Vertebrae}

(Figures 7-29)

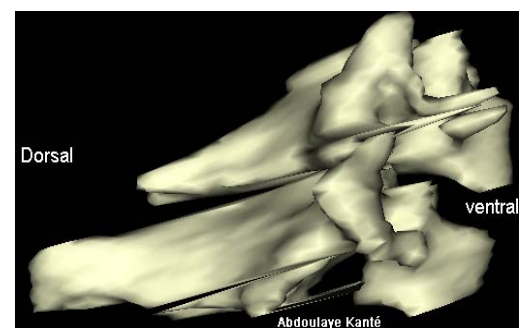

Figure 7. Right lateral view of the C6-C7 vertebrae showing the important thorny process of C7.

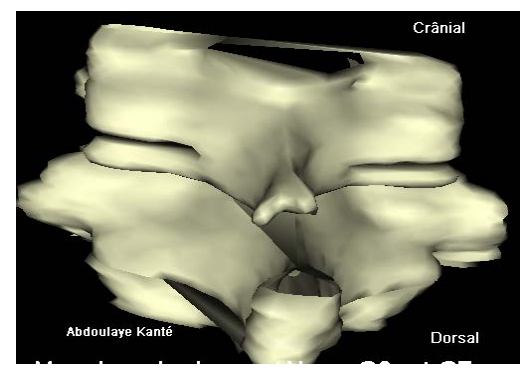

Figure 8. Dorsal view of the C6-C7 vertebrae. Note that the thorny process of C7 is unituberculous.

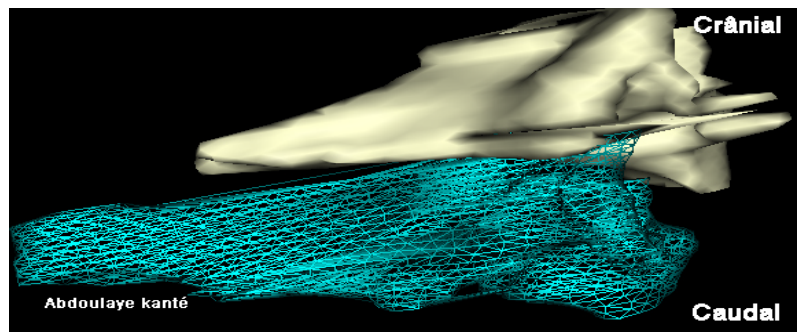

Figure 9. Wireline representation of C7.

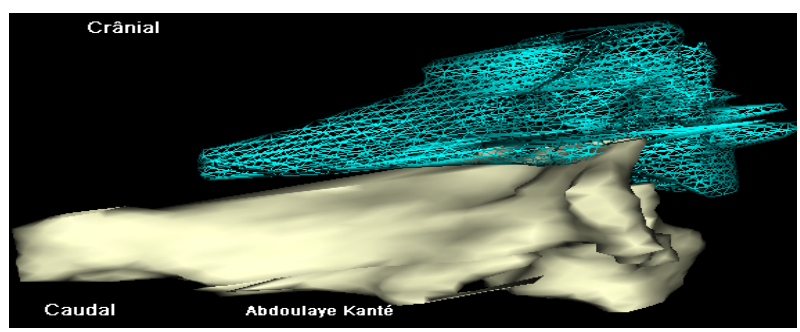

Figure 10. Wireline representation of C6. 


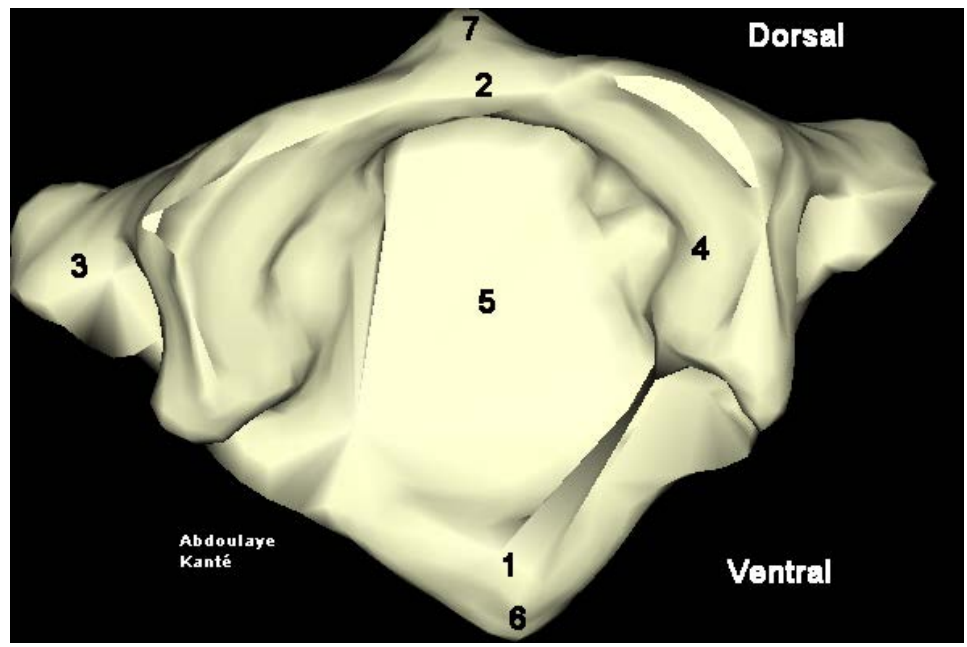

Figure 11. Caudal or lower view of the first cervical vertebra (C1) or atlas. (1. Ventral arch; 2. Dorsal arch; 3. Transverse process; 4. Lateral masses; 5 . Vertebral foramen; 6. Ventral tubercle; 7. Dorsal tubercle).

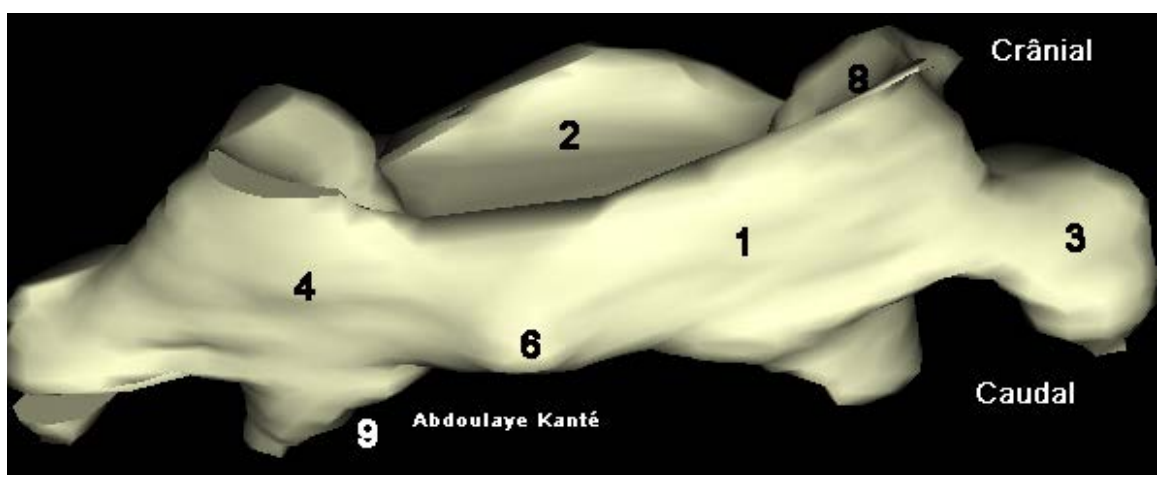

Figure 12. Ventral view of the first cervical vertebra (C1) or atlas [7]. (1. Ventral arch; 2. Dorsal arch; 3. Transverse process; 4. Lateral masses; 5 . Vertebral foramen; 6. Ventral tubercle; 7. Dorsal tuber; 8. Cranial articular facet; 9. Caudal articular facet).

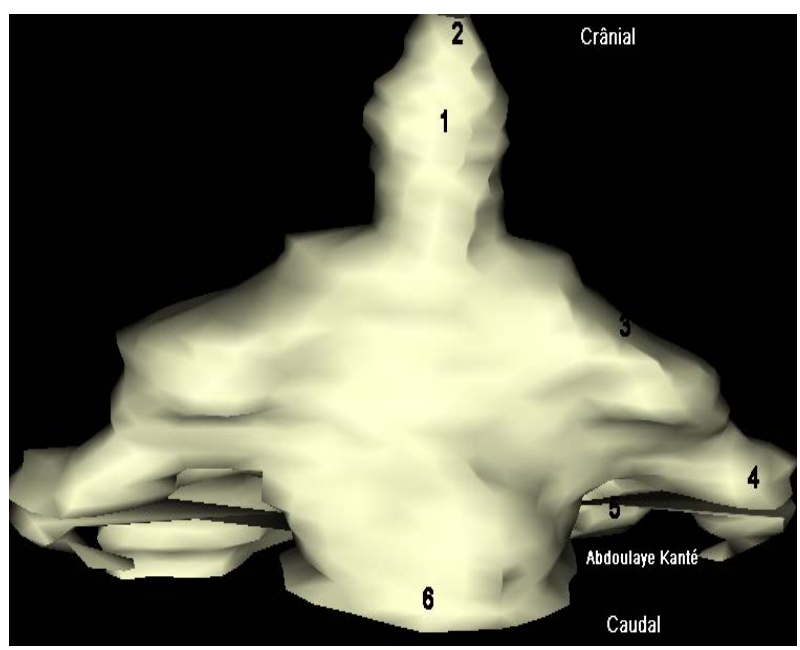

Figure 13. ventral view of the second cervical vertebra (C2) or axis [8]. (1. Atloid ventral articular facet; 2 . Apex of the odontoid process; 3 . Cranial articular facet; 4 . Transverse process; 5 . Caudal articular facet; 6 . Axis beak). 


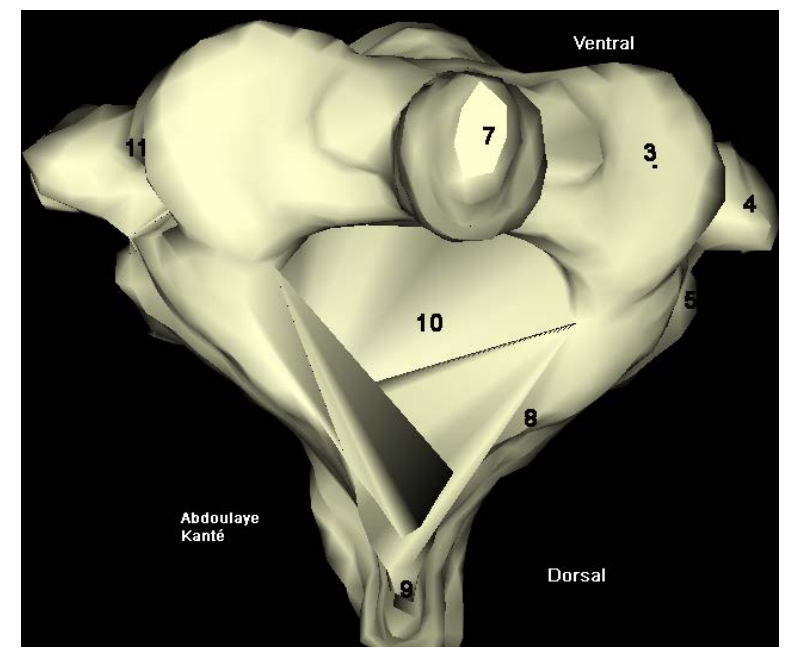

Figure 14. Cranial or upper view of the second cervical vertebra (C2) or the axis. (1. Atloid ventral articular facet; 2 . Apex of the odontoid process; 3. Cranial articular facet; 4. Transverse process; 5 . Caudal articular facet; 6 . Axis beak; 7. Odontoid process; 8 . Blade; 9. Spiny (bifurcated) process; 10. Vertebral foramen; 11. Transverse foramen).

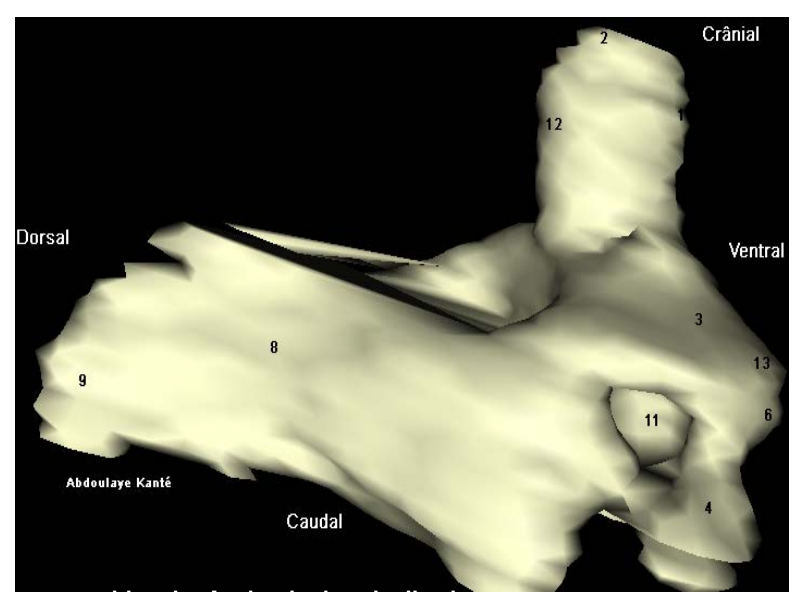

Figure 15. Right lateral view of the second cervical vertebra (C2) or axis. (1. Atloid ventral articular facet; 2. Apex of the odontoid process; 3. Cranial articular facet; 4. Transverse process; 5 . Caudal articular facet; 6. Axis beak; 7. Odontoid process; 8. Blade; 9. Spiny (bifurcated) process; 10. Vertebral foramen; 11. Transverse foramen; 12. Dorsal articular facet of the odontoid; 13. Corps).

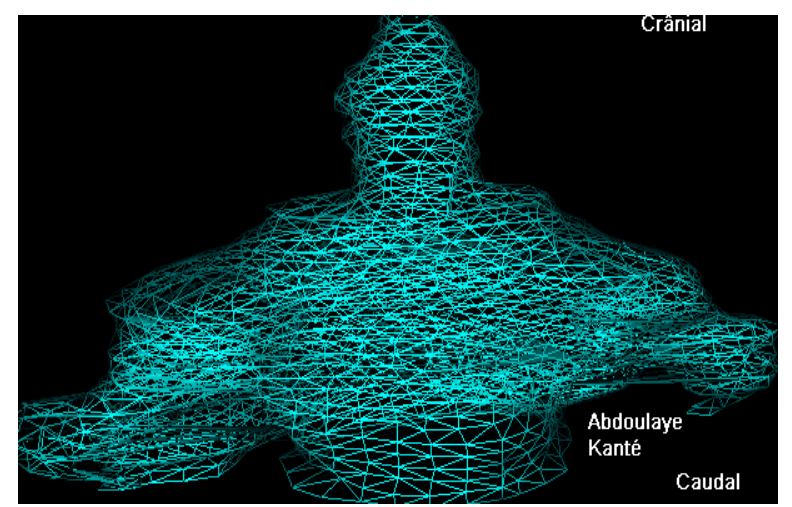

Figure 16. Wired representation of the second cervical vertebra (C2) or axis. 


\subsection{D Vector Reconstruction of Hyoid Bone and Sternal Manubrium}

Here, we will present the $3 \mathrm{D}$ vector reconstruction of the hyoid bone, then that of the sternal manubrium.

\subsubsection{D Vector Reconstruction of the Hyoid Bone (Figures 17-19)}

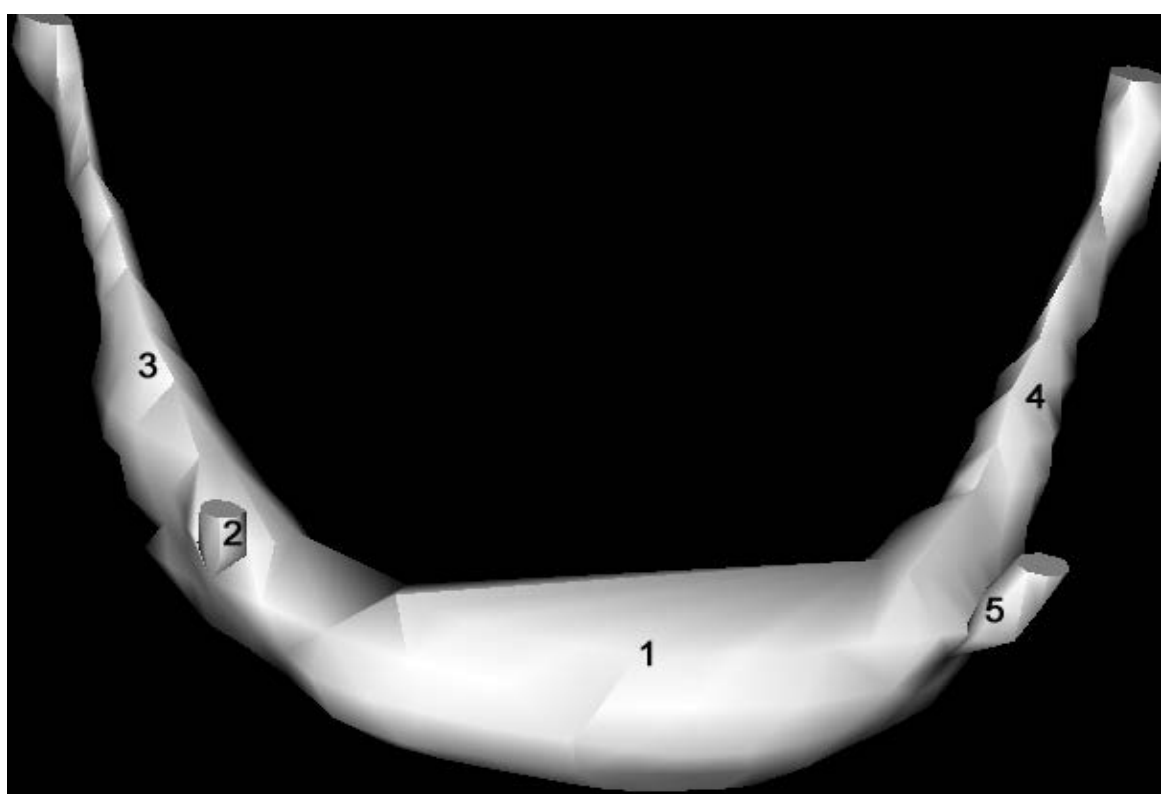

Figure 17. 3D vector reconstruction of hyoid bone: Ventral view. (1. Body; 2. Small right horn; 3. Large right horn; 4. Large left horn; 5. Small left horn).
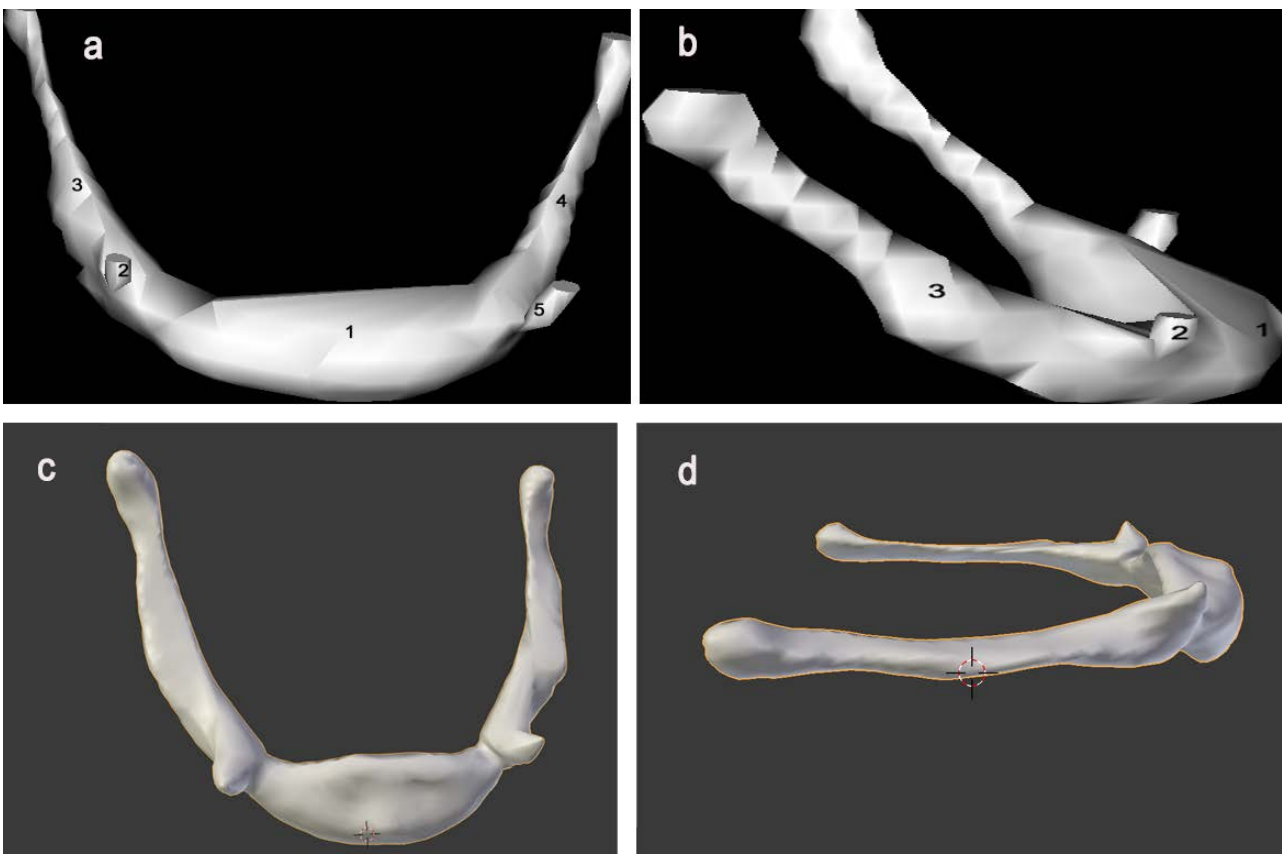

Figure 18. Hyoid bone: (a) Anterior view in Winsurf; (b) Right side view in Winsurf; (c) Previous view in blender; (d) Side view in blender. (1. Body; 2. Small straight horn; 3. Large straight horn; 4. Large left horn; 5. Small left horn). 


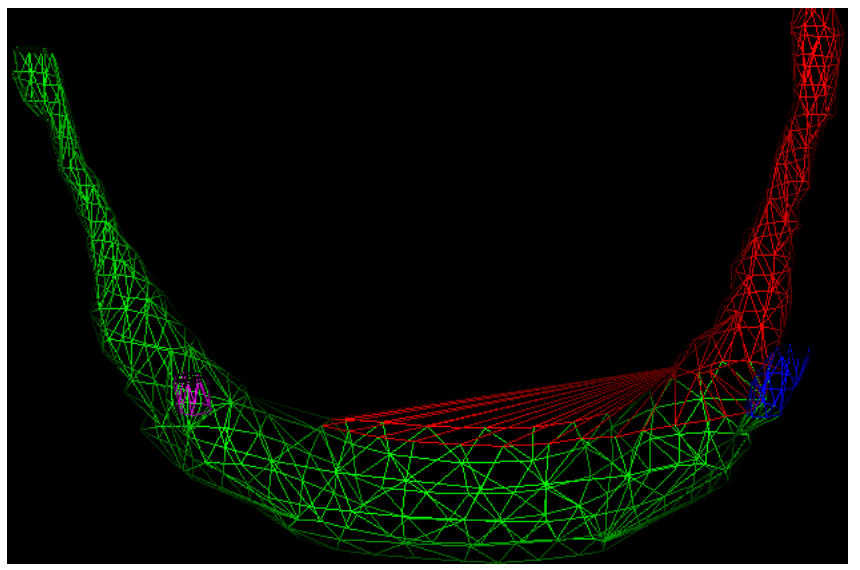

Figure 19. Wired representation of the hyoid bone.

\subsubsection{D Reconstruction Vector of the Sternal Manubrium} (Figures 20-22)

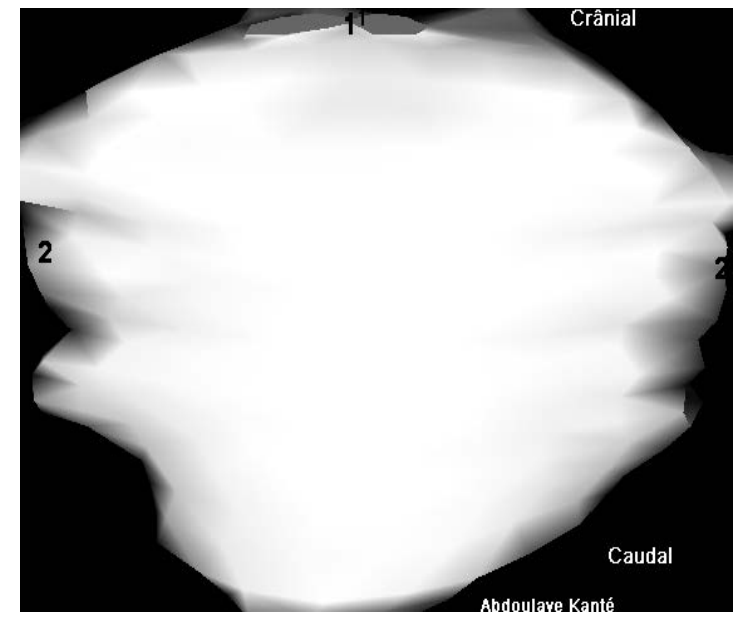

Figure 20. 3D manubrium vector reconstruction: ventral view. (1. Jugular incision of the sternum; 2. Clavicular incision; 3. Costal incision).

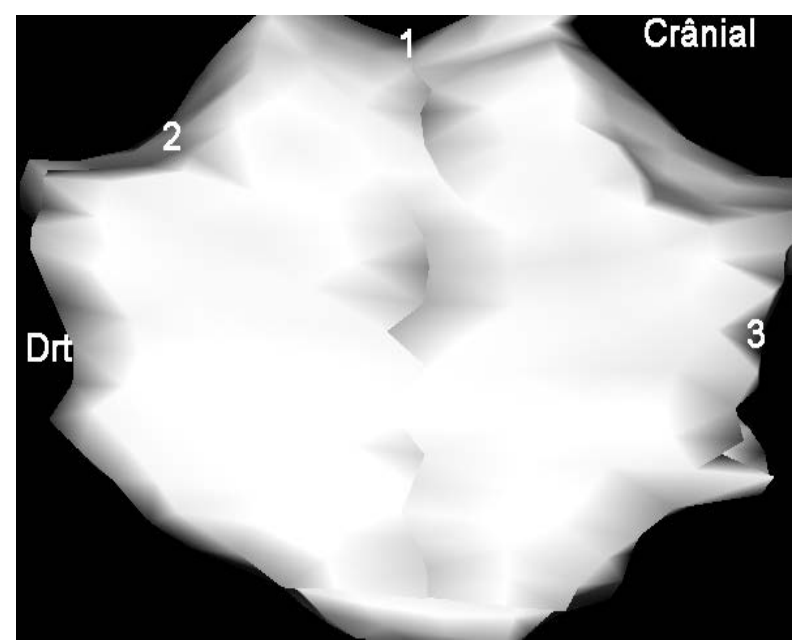

Figure 21. 3D vector manubrium reconstruction: back view. (1. Jugular incision of the sternum; 2. Clavicular incision; 3. Costal incision). 


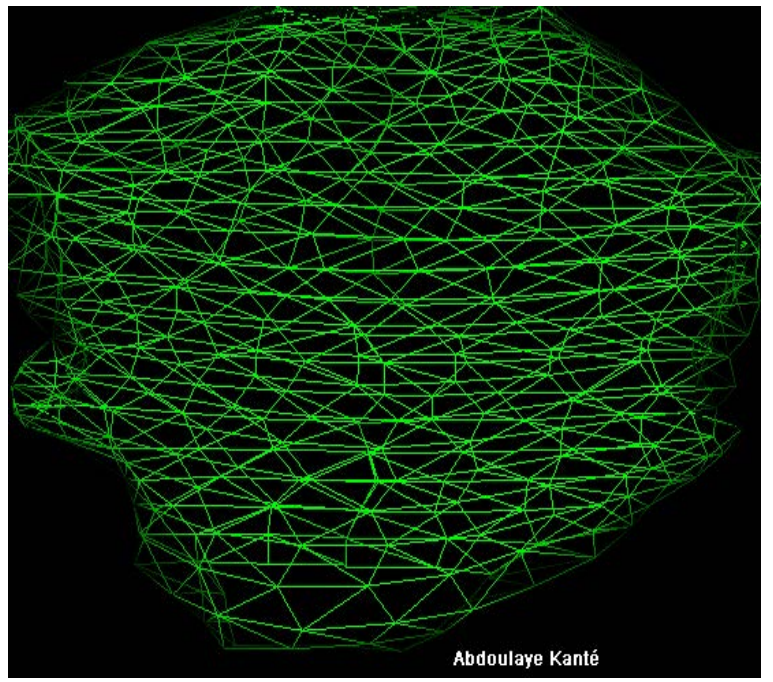

Figure 22. Wireline representation of the manubrium. (1. Jugular incision of the sternum; 2. Clavicular incision; 3. Costal incision).

\subsection{D Vector Reconstruction of the Clavicles (Figures 23-25)}

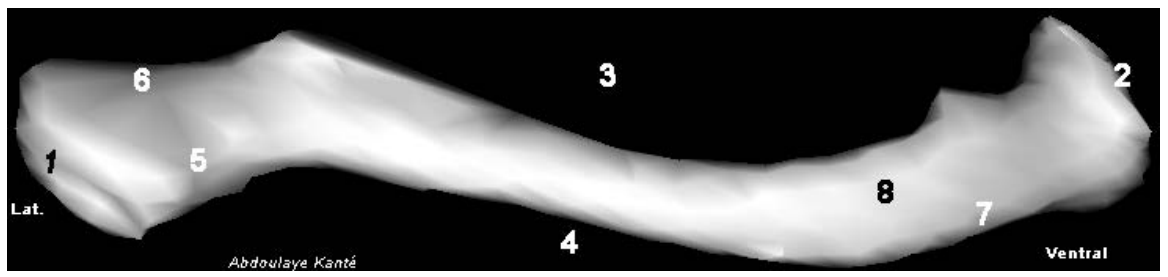

Figure 23. 3D vector reconstruction of the clavicle: cranial or upper view. (1. Acromial joint surface; 2 . Sternal joint surface; 3 . Cranial edge; 4 . Caudal edge; 5 . Deltoid muscle; 6 . Trapezium muscle; 7. Large pectoral muscle; 8. Sterno-cleido-mastoid muscle).

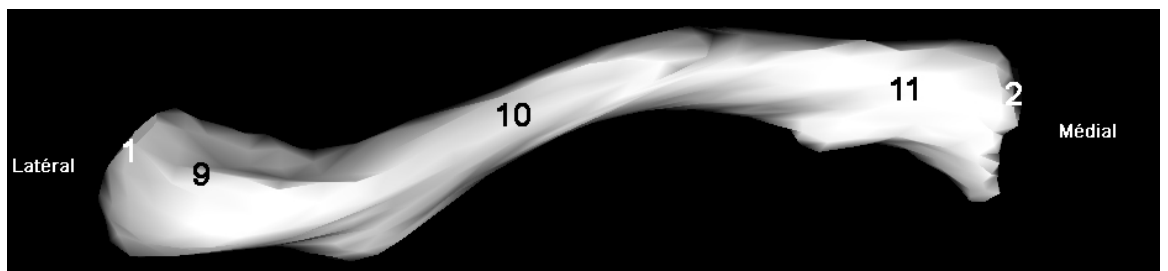

Figure 24. 3D vector reconstruction of the clavicle. Caudal or lower face. (1. Acromial joint surface; 2. Sternal joint surface; 9. Trapezoid line and conoid ligament; 10. Subclavian muscle furrow with muscle insertion; 11. Costo-clavicular ligament).

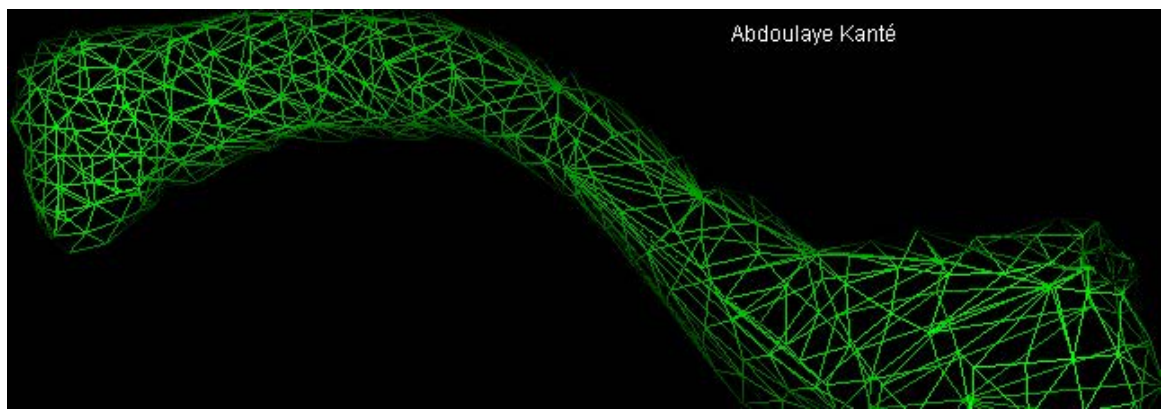

Figure 25. Wired representation of the clavicle. 

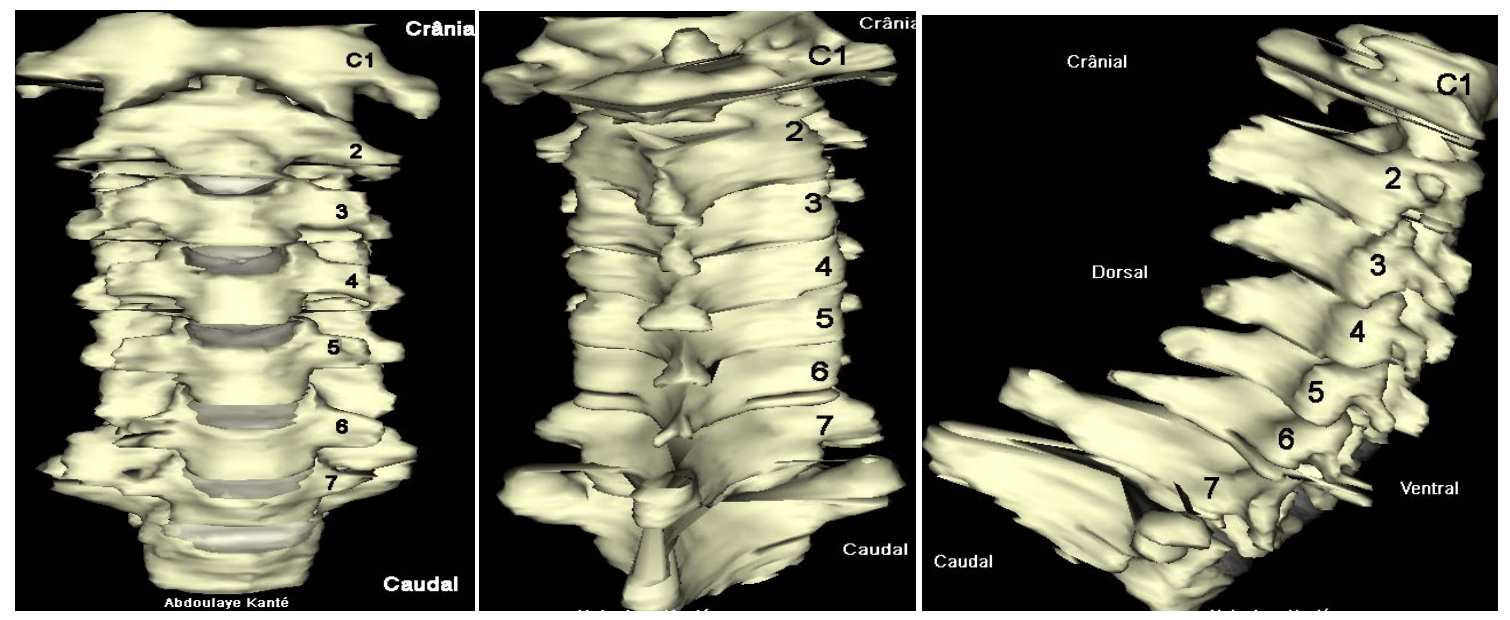

Figure 26. Ventral, dorsal and lateral spines of the cervical skeleton. [C1: Atlas or first cervical vertebra; 2. Axis or second cervical vertebra (C2); 3. Third cervical vertebra or C3; 4 . Fourth cervical vertebra or C4; 5 . Fifth cervical vertebra or C5; 6. Sixth cervical vertebra or C6; 7. Seventh cervical vertebra or C7].

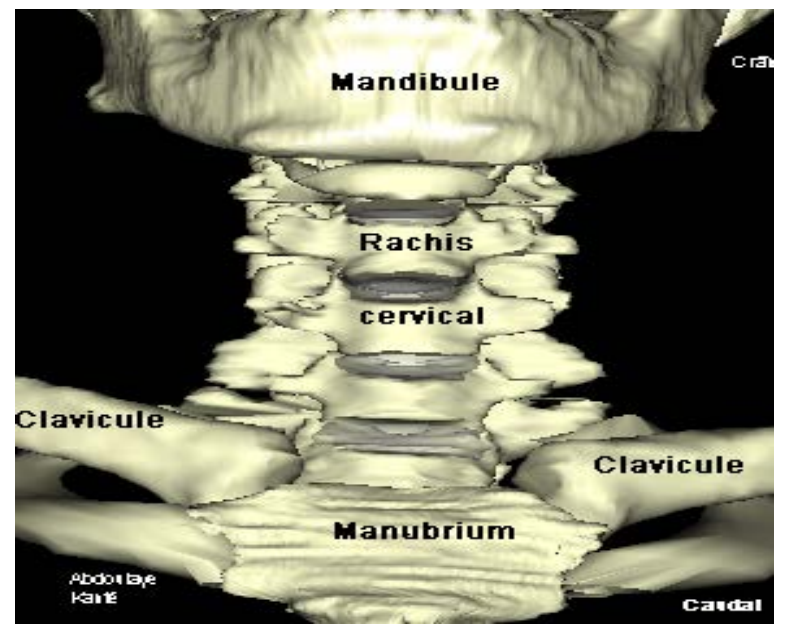

Figure 27. Ventral view of the neck skeleton.

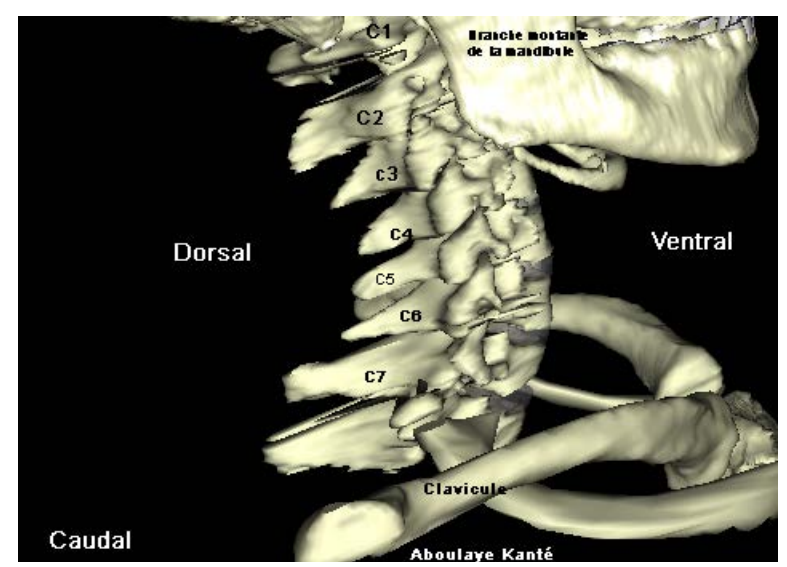

Figure 28. Right side view of the bony neck skeleton.

Our 3D reconstruction of the bony neck skeleton was inserted into the DIVA3D virtual dissection table (Figure 29). 


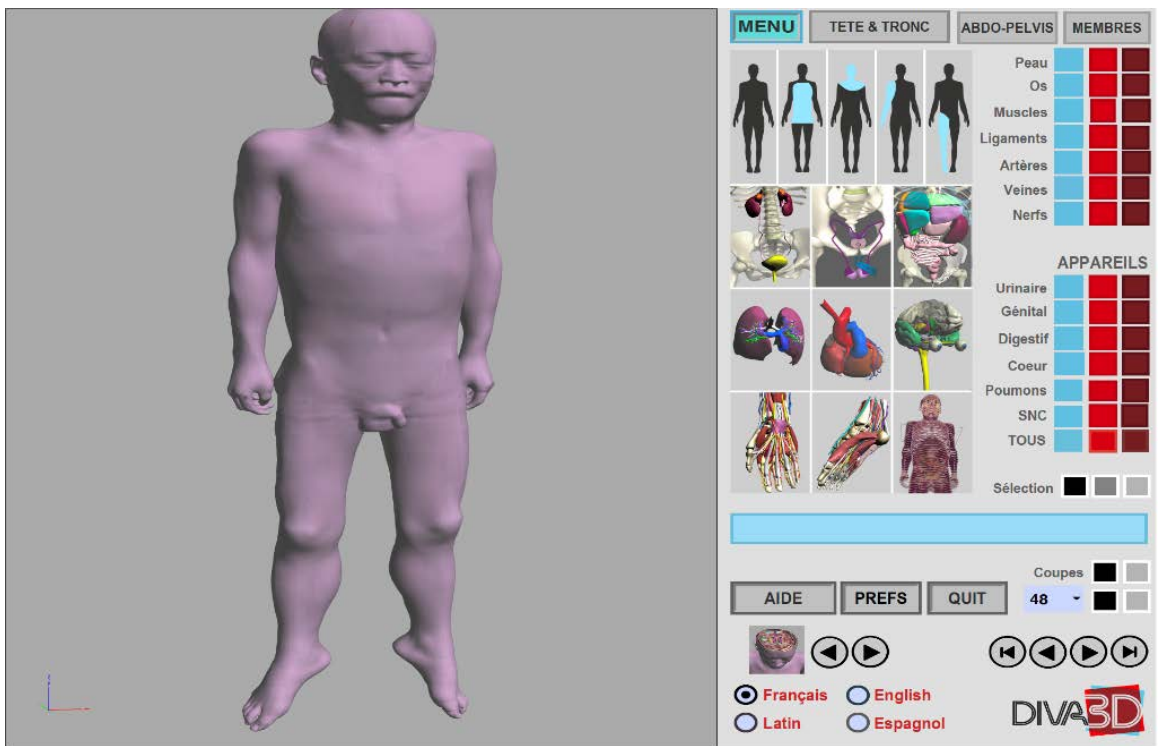

Figure 29. DIVA3D dissection table.

\section{Discussion}

The advantage of our 3D vector modeling of the neck skeleton is essentially based on the fact that the entire work of contouring and therefore the entire 3D reconstruction, was carried out from real slices of the human body. This is followed by a major increase in the accuracy and reliability inherent in the results presented above.

Indeed, automatic reconstructions of the neck skeleton from digital processes such as MRI and CT may be somewhat disappointing in the sense that some bone structures are absent. In contrast to this process, this contouring work is based on manual segmentation, which is based on anatomical expertise, which reduces the risk of errors in reconstruction.

The second advantage lies in the fact that greater precision and the possibility of individualization of the different bony structures of the neck promote a massive application in the academic field thus contributing to a better understanding by students in medicine and other fields. Furthermore, it is fundamental to emphasize that this application is not restricted to the academic field but can also be the support of a "Surgical Training". This allows surgeons to continue training and, a fortiori, to improve their ability in their daily practices.

In addition, the anatomical slices are of very high resolution unlike those of the Korean team working on segmented slices. In addition, the slice intervals were relatively reduced $(0.2 \mathrm{~mm}$ vs $1.0 \mathrm{~mm}$ in the $\mathrm{KVH})$ which greatly facilitates our work of contouring especially in tracking the path of complex entities such as bone processes.

Finally, it is clear that "Winsurf" and Acrobat 3D PDF are particularly easy to take in hand software, which is not the case of other $3 \mathrm{D}$ modeling and manual segmentation software. In addition, they offer a wide range of textures, which increases the realism that we can bring to our final work. 
Our 3D modelling of the neck skeleton clearly demonstrates the technological advances being made in the medical and scientific field in general. It is a remarkable tool for teaching neck osteology in faculties of health.

\section{Conclusion}

Our 3D modeling of the neck skeleton is an original educational tool that can easily teach neck osteology and can also serve as a 3D atlas for simulation purposes for training medical gestures.

\section{Acknowledgements}

We thank Mr. Park and Mr. Chung for making the anatomical cuts of KVH available to us.

\section{Conflicts of Interest}

The authors declare no conflicts of interest regarding the publication of this paper.

\section{References}

[1] Schunke, M., Schulte, E., Schumacher, U., Voll, M. and Wesker, K. (2016) Head, Neck and Neck Fasciae. Prometheus Anatomy Atlas. Head, Neck and Neuroanatomy, Deboeck D Superior, Paris, 4.

[2] Bargy, F. and Beaudoin, S. (2010) Regions. In the Keys to Anatomy. Ellipses, Paris, (FR), 172.

[3] Park, J.S., Chung, M.S., Hwang, S.B., Lee, Y.S., Har, D.H. and Park, H.S. (2005) Visible Korean Human: Improved Serially Sectioned Images of the Entire Body. IEEE Transactions on Medical Imaging, 24, 352-360. https://doi.org/10.1109/TMI.2004.842454

[4] Park, J.S., Chung, M.S., Hwang, S.B., Lee, Y.S., Har, D.H. and Park, H.S. (2005) Technical Report on Semiautomatic Segmentation by Using the Adobe Photoshop. Journal of Digital Imaging, 18, 333-343. https://doi.org/10.1007/s10278-005-6704-1

[5] Park, J.S., Chung, M.S., Hwang, S.B., Shin, B.S. and Park, H.S. (2006) Visible Korean Human: Its Techniques and Applications. Clinical Anatom, 19, 216-224. https://doi.org/10.1002/ca.20275

[6] Park, J.S., Chung, M.S., Shin, D.S., Har, D.H., Cho, Z.H., Kim, Y.B., Han, J.Y. and Chi, J.G. (2009) Sectioned Images of the Cadaver Head Including the Brain and Correspondences with Ultrahigh Field 7.0 T MRIs. Proceedings of the IEEE, 97, 1988-1996. https://doi.org/10.1109/JPROC.2009.2025524

[7] Kante, A., Daou, M., Coulibali, B., Uhl. J.F., Delmas, V., Chevallier, J.M., Ba, B. and Ongoiba, N. (2020) 3D Vector Reconstruction of the Atlas from Anatomical Sections of Korean Visible Human at the Laboratory of Clinical and Digital Anatomy of Paris Descartes University. The Asian Institute of Research Journal of Health and Medical Sciences, 3, 260-269. https://doi.org/10.4236/fmar.2020.83006

[8] Kanté, A., Daou, M., Coulibaly, B., Uhl, J.F., Delmas, V. and Ongoïba, N. (2020) 3D Vector Reconstruction of the Axis from the Anatomical Sections of Korean Visible Human at the Laboratory of Clinical and Digital Anatomy of Paris Descartes University. International Journal of Medical, 4, 260-269. 